\title{
Tratamiento farmacológico en pacientes con COVID-19: una revisión integradora
}

\author{
Pharmacologic treatment in patients with COVID-19: an integrative \\ review
}

\section{Tratamento farmacológico em pacientes com COVID-19: uma revisão integrativa}

\author{
Esthela Carolina Melendrez-Arango ${ }^{1}$ \\ (iD https://orcid.org/0000-0001-9142-6098 \\ María Lorena Durán-Aguirre ${ }^{1}$ \\ (iD) https://orcid.org/0000-0003-3437-9277 \\ Lourdes Quiñones-Lucero ${ }^{1}$ \\ (iD) https://orcid.org/0000-0002-0944-6848 \\ Sandra Lidia Peralta-Peña ${ }^{2}$ \\ (i) https://orcid.org/000-0001-8534-2250 \\ María Rubi Vargas ${ }^{2 *}$ \\ (iDhttps://orcid.org/0000-0002-1075-5576
}

1. Estudiante de Licenciatura en Enfermería. Universidad de Sonora. Departamento de Enfermería. Hermosillo, Sonora, México.

2. Doctora en Ciencias de Enfermería. Profesor de Tiempo Completo. Departamento de Enfermería. Universidad de Sonora. Hermosillo, Sonora, México.

*Autor para correspondencia: rubi.vargas@unison.mx

Recibido: 08/12/2021

Aceptado: $22 / 11 / 2020$ 


\section{Resumen}

Introducción: La salud hoy más que nunca ha sido vulnerada, la humanidad está sufriendo por la invasión del coronavirus SARS-CoV-2, que ha expuesto al mundo a la peor emergencia sanitaria en este siglo. La comunidad científica y los sistemas de salud global conjuntan esfuerzos en la búsqueda de un tratamiento definitivo, a la fecha se reconoce que la terapia está dirigida a mitigar los síntomas. Objetivo: Identificar las evidencias científicas sobre el tratamiento farmacológico en los pacientes con COVID-19. Metodología: Se realizó una revisión integradora de la literatura publicada de diciembre 2019 a octubre 2020, en los sistemas de información Clinical Key, Dialnet, EBSCO Host y Scopus, mediante los descriptores Coronavirus Infections, COVID-19, Drug therapy, tratamiento farmacológico. Los criterios de selección fueron artículos de investigación cuantitativa de cualquier tipo de diseño_en inglés y español disponibles a texto completo, obteniéndose una muestra de 24 artículos. Resultados: La mayoría de los estudios fueron revisiones integrativas con $66.6 \%$ y ensayos clínicos o in vitro con $12.5 \%$. Se identificaron en la terapia farmacológica nueve medicamentos de mayor uso en COVID-19: Hidroxicloroquina/_lloroquina, lopinavir/ritonavir, remdesivir, azzitromicina, ivermectina, tocilizumab y dexametasona, no obstante, solo cuatro fármacos mostraron efectividad significativa según la evidencia científica. Conclusiones: remdesivir demostró mayor efectividad y seguridad en el tratamiento, tocilizumab y dexametasona mostraron resultados favorables, sin embargo, los resultados no son contundentes. Los autores señalan que aún no es posible afirmar que se dispone de tratamientos que combata la COVID-19 efectivamente.

Palabras clave: COVID-19; Infecciones por coronavirus; Tratamiento farmacológico (DeCS, MeSH).

\section{Abstract}

Introduction: Today more than ever human health has been compromised; humanity is suffering from the invasion of the SARS-CoV-2 coronavirus, which has exposed the world to the worst health emergency in this century. Although the scientific community and global health systems are joining efforts in the search for a definitive treatment, to date it is recognized that the therapy is aimed at mitigating the symptoms. Objective: Identify scientific evidence on pharmacological treatment for patients with COVID-19. Methodology: An integrative review of literature published from December 2019 to October 2020, in the following information systems Clinical Key, Dialnet, EBSCO Host and Scopus was performed using the descriptors Coronavirus Infections, COVID-19, Drug therapy, and pharmacological treatment. The selection criteria were quantitative research articles of any type of design, in English and Spanish, available in full text, obtaining a sample of 24 articles. Results: Most of the studies were integrative reviews with a percentage of 66.6 and clinical or in vitro trials with a percentage of 12.5. Nine drugs of major use in COVID-19 were identified in the drug therapy, that is, Hydroxychloroquine/Chloroquine, Lopinavir/Ritonavir, Remdesivir, Azithromycin, Ivermectin, Tocilizumab and Dexamethasone. However, According to the scientific evidence only four drugs showed significant effectiveness. Conclusions: Remdesivir demonstrated greater effectiveness and safety during the treatment, and Tocilizumab and Dexamethasone showed favorable results. Nevertheless, the results are not conclusive. The authors pointed out that so far is not possible to conclude there are treatments that effectively fight COVID-19.

Keywords: COVID-19; Coronavirus Infections; Pharmacological Treatment (DeCS, MeSH). 


\begin{abstract}
Abstrato
Introdução: Hoje, mais do que nunca, a saúde humana foi comprometida; a humanidade está sofrendo com a invasão do coronavírus SARS-CoV-2, que expôs o mundo à pior emergência sanitária deste século. Embora a comunidade científica e os sistemas globais de saúde estejam unindo esforços na busca por um tratamento definitivo, até o momento é reconhecido que a terapia visa mitigar os sintomas. Identificar evidências científicas sobre o tratamento farmacológico de pacientes com COVID-19.Objetivo: Identificar evidências científicas sobre o tratamento farmacológico para pacientes com COVID-19.Metodologia: Foi realizada uma revisão integrativa da literatura publicada de dezembro de 2019 a outubro de 2020, nos seguintes sistemas de informação Clinical Key, Dialnet, EBSCO Host e Scopus utilizando os descritores Coronavirus Infections, COVID-19, Drug therapy, and pharmacological treatment. Os critérios de seleção foram artigos de pesquisa quantitativa, de qualquer tipo de delineamento, nos idiomas inglês e espanhol, disponíveis na íntegra, obtendo-se uma amostra de 24 artigos. Resultados: A maioria dos estudos foram revisões integrativas com percentual de 66,6 e ensaios clínicos ou in vitro com percentual de 12,5 . Nove medicamentos de maior uso no COVID-19 foram identificados na terapia medicamentosa, ou seja, Hidroxicloroquina/Cloroquina, Lopinavir/Ritonavir, Remdesivir, Azitromicina, Ivermectina, Tocilizumabe e Dexametasona. No entanto, de acordo com as evidências científicas, apenas quatro medicamentos mostraram eficácia significativa. Conclusões: De acordo com as evidências científicas, apenas quatro medicamentos mostraram eficácia significativa. Conclusões: Remdesivir demonstrou maior eficácia e segurança durante o tratamento, e Tocilizumabe e Dexametasona apresentaram resultados favoráveis. No entanto, os resultados não são conclusivos. Os autores apontaram que até o momento não é possível concluir que existam tratamentos que combatam efetivamente o COVID-19.
\end{abstract}

Palavras-chave: COVID-19; Infecções por Coronavírus; Tratamento Farmacológico (DeCS).

\title{
Introducción
}

En el contexto internacional existe un consenso sobre la situación compleja que guarda la salud hoy en día, misma que se ha intensificado por el impacto de la pandemia COVID-19 que ha expuesto al mundo a la peor emergencia sanitaria en este siglo, con enormes costos humanos, económicos y sociales ${ }^{(1)}$. El síndrome respiratorio agudo ocasionado por el coronavirus 2 (SARS-CoV-2) mejor conocido como COVID-19, inició en Wuhan China, en diciembre del 2020 y desde esa fecha se extendió a nivel global, siendo declarado pandemia por la Organización Mundial de la Salud (OMS) el 11 de marzo del 2021.(2) El Comité de Emergencia sobre COVID-19(3) realizó la quinta reunión en octubre del año 2020 donde se examinó la 
situación y su progreso, reiterando que la pandemia era una emergencia de Salud Pública de importancia internacional, notificando a la fecha 44 millones de casos, 28.2 millones de personas recuperadas y poco más de 1.1 millones de decesos por COVID-19. ${ }^{(2-4)}$ Diversos países se conjuntaron para reducir y contener la propagación del virus, realizaron múltiples esfuerzos para descubrir un tratamiento definitivo que mejorará las condiciones de salud de la población, hasta ese momento fue dirigido hacia el manejo y contención de los síntomas, mediante terapia antiviral y transfusión de plasma, porque aún, en ese periodo no se habían descubierto medicamentos y vacuna específicos contra el virus. ${ }^{(3-5)}$

Los coronavirus pertenecen a una gran familia de virus llamados Coronaviridae, los cuales circulan continuamente entre la población humana y se dirigen comúnmente a las vías respiratorias superiores provocando síntomas semejantes al resfriado común. La mayoría de las personas con COVID-19 presentaron enfermedad leve (40\%) o moderada (40\%), pero algunas desarrollaron enfermedad grave (15\%) y crítica (5\%) con complicaciones como insuficiencia respiratoria, síndrome respiratorio agudo, septicemia, tromboembolias e insuficiencia multiorgánica que podrían provocar la muerte. En la enfermedad grave se han señalado como factores de riesgo el tabaquismo, edad avanzada y la comorbilidad de hipertensión, cardiopatías, diabetes y cáncer. ${ }^{(5,6)}$

En la actualidad aún no se han encontrado resultados contundentes de ensayos clínicos aleatorizados sobre una respectiva terapia que mejore los resultados en los casos sospechosos o confirmados con COVID-19 ${ }^{(4,7,8)}$. Se han realizado más de 300 ensayos clínicos de tratamiento activo cuyos hallazgos basados en pruebas relativas a los principales tratamientos propuestos sugieren el empleo de terapias antivirales que incluyen anticuerpos monoclonales y péptidos antivirales que actúan en la glicoproteína de la punta viral, asimismo los inhibidores de enzimas virales, inhibidores de la síntesis viral de ácido nucleico e inhibidores de otras proteínas virales. Otras terapias engloban agentes que potencian la respuesta de interferón en el huésped o afectan las vías de señalización en la replicación viral. ${ }^{(6-9)}$ Es así como actualmente se emplean fármacos antivirales (remdesivir, ribavirina, lopinavir-ritonavir, favipiravir, 
oseltamivir, umifenovir), antipalúdicos (Cloroquina [CQ]) e hidroxicloroquina [HCQ]), agentes inmunomoduladores (Tocilizumab [TCZ] interferones, transfusiones de plasma) y agentes coadyuvantes (Azitromicina [AZI], corticosteroides [CST]), entre otros. Los mecanismos de acción y las medidas farmacológicas ulteriores deberán analizarse a la luz de los resultados de los ensayos clínicos, especialmente en la seguridad y eficacia de cada fármaco. ${ }^{(7-12)}$

Algunos reportes recientes han mostrado efectos terapéuticos contra la infección de la COVID-19, como el uso de $\mathrm{HCQ}^{(10,11)}, \mathrm{AZI}^{(11,12)}$ e ivermectina ${ }^{(13)}$ _sin embargo, aún no sean observado datos consistentes sobre que fármaco tiene mayor eficacia en comparación con otro o si la combinación de ellos puede preservar la vida..$^{3,8,14-17)}$

Siendo la enfermera (o) el principal recurso humano del sistema salud que brinda cuidado las 24 horas y ministra los diversos tratamientos en los pacientes con la COVID-19, es de vital importancia que se mantenga actualizada (o) respecto de los tratamientos farmacológicos más utilizados internacionalmente. Esta revisión pretende responder a la interrogante ¿Cuál es el tratamiento farmacológico y su resultado/efectividad en el control, recuperación y sobrevida en los pacientes con COVID-19?. Por lo anteriormente expuesto, el propósito es identificar las evidencias científicas sobre el tratamiento farmacológico en los pacientes con COVID-19.

\section{Metodología}

Revisión integradora de la literatura aplicando la lectura crítica, ${ }^{(18,19)}$ se utilizó la metodología PICO, que significa:_Paciente (Patient/P): Adultos diagnosticados con COVID-19; Intervención o Tratamiento (Intervention/l): Tratamiento farmacológico utilizado; Comparación__(Comparation/Grupos de tratamiento/C): Comparación entre los diferentes fármacos; Resultado esperado (Outcomes/O): Control, recuperación, sobrevida de los pacientes. Para ello se implementó un plan de búsqueda de información sobre estudios de cualquier tipo de diseño de investigación, publicados de diciembre 2019 a noviembre 2020, en las bases de datos y sistemas de información EBSCO-Host, Scopus, Clinical Key y Dialnet. Se usaron 
las palabras clave extraídas de los Descriptores de Ciencias de la Salud del Centro Latinoamericano y del Caribe (DeCS) ${ }^{(20)}$ : Coronavirus Infections, COVID-19, Drug therapy, tratamiento farmacológico y del Medical Subject Heading de la National Library of Medicine (MeSH) ${ }^{(21)}$ : COVID-19 drug treatment, coronavirus disease 2019 drug treatment, (término introducido en marzo de 2020), otros términos empleados en la búsqueda fueron COVID-19, SARS-CoV-2, tratamiento farmacológico, efectividad de fármacos de COVID19, treatment coronavirus, coronavirus pharmacotherapy, COVID-19, effective pharmacological treatment in COVID-19, combinados los operadores booleanos AND y OR.

La búsqueda de información arrojó 13,382 artículos publicados en inglés (91.6\%) y en español (8.4\%) (Tabla 1). Se eligieron aquellos disponibles en extenso en ambos idiomas que abordaran las variables de estudio en la población adulta, se eliminaron 13,358 artículos repetidos y donde no se localizó el documento extenso.

Tabla 1. Sistema de información y estrategia de búsqueda de artículos sobre tratamiento farmacológico en pacientes con COVID-19, $(n=13,382)$.

\begin{tabular}{lll}
\hline $\begin{array}{c}\text { Sistema de información } \\
\text { base de datos }\end{array}$ & Estrategia de búsqueda & \multicolumn{1}{c}{ Artículos } \\
\hline Clinical Key & 1. COVID AND tratamiento & 1. Español: $305 ;$ Inglés: 5531 \\
& $\begin{array}{l}\text { 2. Coronavirus tratamiento OR COVID } \\
\text { SAR2 }\end{array}$ & 2. Español: $366 ;$ Inglés: 6265 \\
& $\begin{array}{l}\text { 3. COVID AND Pharmacotherapy. } \\
\text { 1. COVID - 19 AND tratamiento }\end{array}$ & 3. Español: $12 ;$ Inglés: 83 \\
EBSCO Host & 1. Español: 190 \\
2. COVID - 19 AND drugs & 2. Inglés: 152 \\
SCOPUS & 1. SARS-CoV-2 AND farmacoterapia & 1. Español: 26 \\
& 2. SARS-CoV-2 AND pharmacotherapy & \\
OR COVID-19 treatment & 2. Inglés: 137 \\
Dialnet & 1. COVID AND tratamiento & 1. Español: 211 \\
& 2. SARS-CoV-2 AND tratamiento & 2. Español: 4 \\
\hline
\end{tabular}

Fuente: Elaboración propia

Posterior a la lectura crítica y en apego a los criterios establecidos que dieran respuesta a la pregunta PICO de investigación, la muestra quedo constituida por 24 artículos. En la recolección, análisis y presentación de datos se apoyó con el uso de tablas que presentan la información de los estudios seleccionados como autores, año, país, objetivo, métodos, resultados y conclusiones. 


\section{Resultados}

La literatura consultada fue publicada en el año 2020, perteneciente a los países de EUA (20.8\%), España (12.5\%), China, Ecuador, Colombia y Perú con 8.3\% cada uno, y de otros países como India, Arabia, Inglaterra, Portugal, Cuba y México con 4.2\% respectivamente. Referente al idioma de la publicación $54.2 \%$ fueron en español y $45.8 \%$ en inglés. En el diseño de investigación un $66.6 \%$ era revisión integrativa, $12.5 \%$ ensayos clínicos o in vitro, 8.3\% revisión sistemática y meta-análisis, y el 4.2\% restante correspondió a otros tipos de diseño.

De acuerdo con la lectura crítica, el tratamiento farmacológico contra COVID-19 se clasificó en grupos según su efecto y potencia, observándose los siguientes grupos: antivirales diversos solos o combinados, entre ellos remdesivir, rivafarina, lopinavir/ritonavir, faviparir, oseltamivir, umifenovir, emtricitabina/tenofovir/alafenamida. $(5,16,17,25-28,30,31,33,35-37)$ Otros fármacos como antipalúdicos, antiparasitarios y antibacterianos con efecto antiviral en SARS-CoV-2 fueron CQ, HCQ sola o combinada con AZI e ivermectina ${ }^{(5,14,23,25,28,29,32,34-36)}$ nitazoxanida, teicoplanina, azitromicina y ceftriaxona(5,14,23). Fármacos antiinflamatorios como corticoides, metilprednisolona, dexametasona y prednisona. ${ }^{(5,17,22,24,28)}$ Fármacos

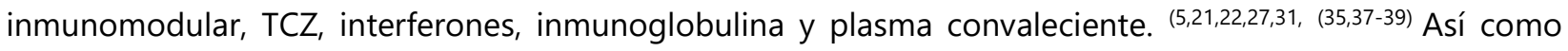
fármacos anticoagulantes como heparina y enoxaparina. ${ }^{(35)}$

Del total de los estudios según la evidencia científica, solo cuatro fármacos mostraron efectividad significativa, remdesivir demostró mayor efectividad y seguridad en el tratamiento, tocilizumab y dexametasona mostraron resultados favorables, sin embargo, los resultados no son contundentes._A continuación, se muestra la información más relevante del análisis de los estudios seleccionados (Tabla 2). 
Tabla 2. Tratamiento farmacológico en pacientes con COVID-19 $(n=24)$.

\begin{tabular}{|c|c|c|c|c|c|}
\hline Autor, Año & País & Objetivos & Métodos & Resultados principales & Conclusiones \\
\hline $\begin{array}{l}\text { Choudhary } R^{\prime} \\
\text { Sharma AK }{ }^{(14)}\end{array}$ & India & $\begin{array}{l}\text { Presentar los } \\
\text { conocimientos } \\
\text { de las } \\
\text { principales } \\
\text { investigaciones } \\
\text { sobre los } \\
\text { medicamentos } \\
\text { ivermectina, } \\
\text { HCQ y AZl en el } \\
\text { contexto de la } \\
\text { emergencia } \\
\text { sanitaria actual. }\end{array}$ & $\begin{array}{l}\text { Muestra } \\
\text { especificada }\end{array}$ & $\begin{array}{l}\text { Ensayos clínicos revelaron el } \\
\text { efecto potencial de la HCQ en el } \\
\text { síndrome respiratorio agudo por } \\
\text { coronavirus, ivermectina mostró } \\
\text { inhibición en la replicación viral. } \\
\text { En ensayos in vitro se redujo el } \\
\text { virus } 5000 \text { veces más en } 48 \\
\text { horas. La AZI mostró alto poder } \\
\text { terapéutico y puede actuar } \\
\text { como profiláctico para disminuir } \\
\text { la tasa de infección de COVID- } \\
19 \text {. }\end{array}$ & $\begin{array}{l}\text { La } \mathrm{HCQ} \text {, ivermectina } \\
\text { y AZI, tienen efecto } \\
\text { potencial contra la } \\
\text { infección de } \\
\text { coronavirus, sin } \\
\text { embargo, su eficacia } \\
\text { debe estudiarse en } \\
\text { detalle en mayores } \\
\text { ensayos clínicos. }\end{array}$ \\
\hline $\begin{array}{l}\text { Fan L, Jiang, S, } \\
\text { Yang X, Wang } \\
Z_{-}^{(22)}\end{array}$ & China & $\begin{array}{l}\text { Examinar los } \\
\text { fármacos } \\
\text { utilizados para el } \\
\text { tratamiento } \\
\text { emergente de } \\
\text { COVID-19 en } \\
\text { China. }\end{array}$ & $\begin{array}{l}\text { Revisión Integrativa } \\
\text { Muestra } \\
\text { especificada }\end{array}$ & 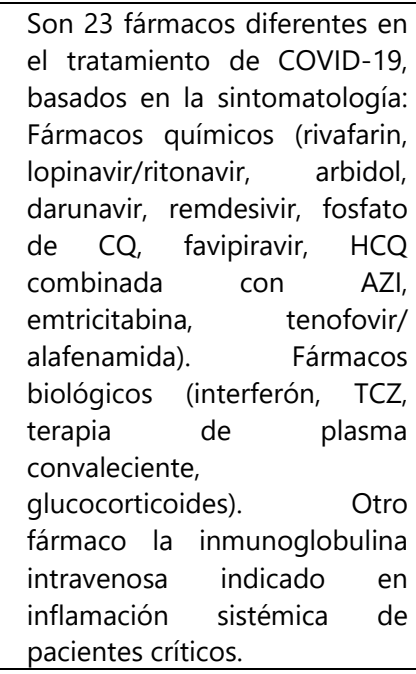 & $\begin{array}{l}\text { Aun no hay } \\
\text { medicamentos } \\
\text { antivirales específicos } \\
\text { para COVID-19. Los } \\
\text { fármacos que se usan } \\
\text { se basan en las } \\
\text { experiencias de } \\
\text { tratamientos } \\
\text { anteriores en virus } \\
\text { como SARS, MERS y } \\
\text { otros. La eficacia y la } \\
\text { seguridad de los } \\
\text { fármacos deben ser } \\
\text { indagados en más } \\
\text { ensayos clínicos. }\end{array}$ \\
\hline $\begin{array}{lr}\text { Tzu-Han } & \text { Y, } \\
\text { Chian-Ying } & C_{1} \\
\text { Yi-Fan } & Y, \\
\text { Chian-Shiu } & C \\
\text { Aliaksandr } & \text { AY, } \\
\text { Tzu-Ying Y, } \\
\text { Cheng-Hsuan } \\
\text { L, et al. }{ }^{(23)}\end{array}$ & China & $\begin{array}{l}\text { Mostrar la } \\
\text { efectividad } \\
\text { farmacológica } \\
\text { de HCQ/CQ en } \\
\text { COVID-19 }\end{array}$ & $\begin{array}{l}\text { Revisión sistemática } \\
\text { y meta-análisis, } \mathrm{n}=9 \\
\text { ensayos que } \\
\text { incluyeron a } 4,112 \\
\text { pacientes. Análisis } \\
\text { en grupos con } \\
\text { diferente nivel de la } \\
\text { enfermedad y } \\
\text { periodo ( } \leq 14 \text { días, } \\
>14 \text { días), así como } \\
\text { dosis de HCQ, } \leq \\
400 \text { mg/día) y }>400 \\
\text { mg día) }\end{array}$ & $\begin{array}{l}\text { La combinación de HCQ-AZI en } \\
\text { pacientes con COVID-19 mostró } \\
\text { mayores beneficios en la } \\
\text { eliminación del virus (OR 27.18, } \\
\text { IC } 95 \% \text { : } 1.29-574.32 \text { ), en relación } \\
\text { del aumento en la tasa de } \\
\text { mortalidad (OR 2.34, IC 95\%: } \\
1.63-3.36 \text { ). } \\
\text { El tratamiento podría reducir la } \\
\text { tasa de mortalidad y la } \\
\text { progresión a una enfermedad } \\
\text { grave en los pacientes COVID-19 } \\
\text { gravemente infectados (OR } 0.27 ; \\
\text { IC 95\%: } 0.13-0.58 \text { ). Un menor } \\
\text { riesgo de mortalidad se observó } \\
\text { en el grupo estratificado del } \\
\text { período de >14 días (OR } 0.27 \text {, } \\
95 \% \text { Cl } 0.13-0.58 \text { ) vs el grupo } \\
\leq 14 \text { días de seguimiento que a } \\
\text { la inversa mostró un aumento en } \\
\text { la tasa de mortalidad (OR } 2.09, \text { IC } \\
\text { del } 95 \%: 1.41-3.10 \text { ) }\end{array}$ & $\begin{array}{l}\text { HCQ-AZI_mostró } \\
\text { beneficios_asociados } \\
\text { con la eliminación del } \\
\text { virus en los pacientes, } \\
\text { y disminución de la } \\
\text { tasa de mortalidad en } \\
\text { COVID-19. } \\
\text { requiere de estudios } \\
\text { más rigurosos, a gran } \\
\text { escala y de periodos } \\
\text { más largo de } \\
\text { seguimiento en los } \\
\text { pacientes } \\
\text { COVID-19. }\end{array}$ \\
\hline
\end{tabular}



Reina J. (26) España $\quad \begin{aligned} & \text { Demostrar la } \\ & \text { eficacia antiviral } \\ & \text { del remdesivir }\end{aligned}$
Revisión integrativa

Muestra

especificada
Remdesivir mostró in vitro y en animales elevada capacidad para

no bloquear la infección y replicación viral con concentraciones alcanzables en el plasma humano. Todos los estudios se realizaron con SARSCoV-2 y MERS-CoV parece que por analogía virológica y funcional, remdesivir es de los pocos que han demostrada eficacia.

Wayah S, Auta Nigeria

$R$, Waziri $P$, Haruna $E_{.}^{(16)}$

Se exponen grupos de fármacos
con diversos efectos: Fármacos receptores del huésped o las

Indagar los
fármacos
dirigidos a los
receptores de
superficie de las
células huésped
necesarios para
la infección por
el SARS-CoV-2 y
examinar los
medicamentos
que pueden
modificar la
respuesta
inmunitaria del
huésped para
lograr la
eliminación
vírica

dirigidos a los superficie de las células huésped necesarios para la infección por el SARS-CoV-2 y examinar los medicamentos que pueden modificar la respuesta inmunitaria del huesped para eliminación vírica

Revisión integrativa
especificada no
enzimas en la célula del virus, enzima de angiotensina 2 (ACES-2), los que actúan en la proteasa de la transmembrana proteínica (TMPRS2) antibacterianos sistémicos efectivos. Fármacos actúan en los gangliósidos de la célula huésped para reducir carga viral, como CQ, $\mathrm{HCQ}$, aún más potente. Fármacos que inhiben el RNA viral validado en diversos ensayos cómo remdesivir. Otros cómo terapia de anticuerpos, inmunomoduladores anticoagulantes para estimular respuesta del huésped.

\section{lar} China fue quien desarrolló

\begin{tabular}{cl}
\hline Marto N, Portugal & Analizar el \\
Monteiro E. (25) & posicionamiento \\
& de organismos \\
& de salud de todo \\
& el mundo en \\
& relación con el \\
& uso no indicado \\
& en las etiquetas \\
& de le los \\
& medicamentos \\
& reutilizados o de \\
& los nuevos \\
& medicamentos \\
& en fase de \\
& investigación \\
para tratar la & enfermedad \\
& coronavírica.
\end{tabular}

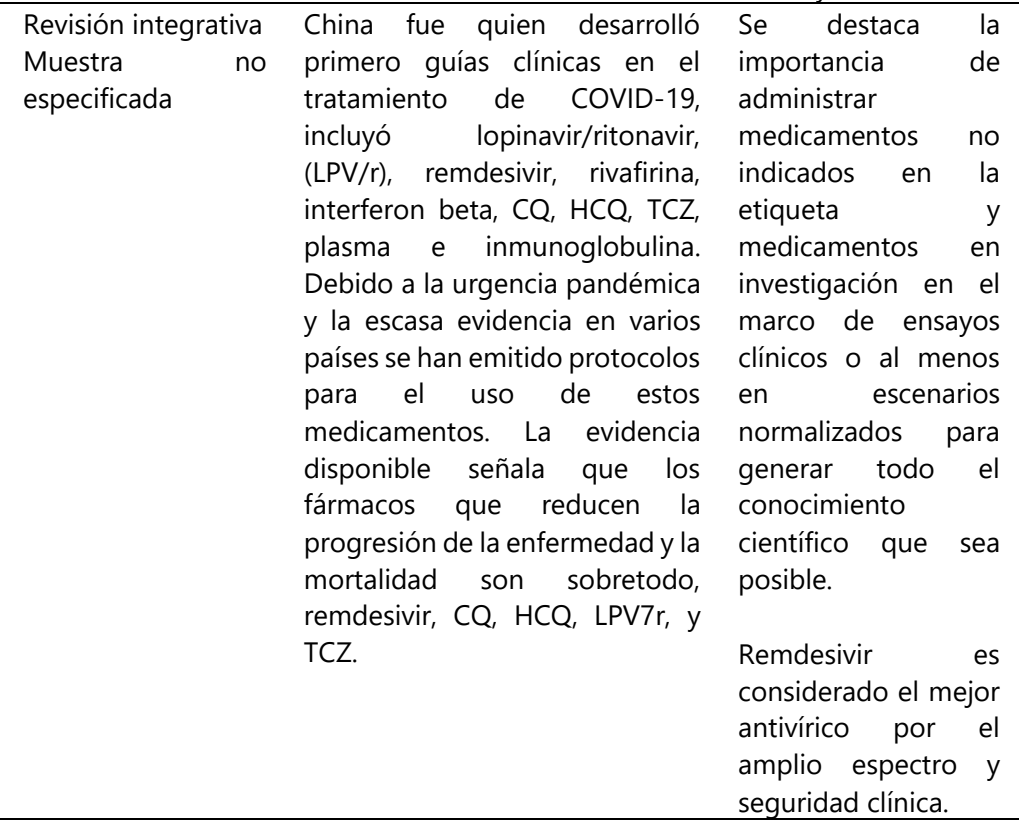

Remdesivir podría ser la esperanza antiviral frente al SARS-CoV2. Se sugiere que éste se ministre las primeras 48 horas, para acortar la replicación viral y disminuir la transmisibilidad.

En la COVID-19, no es suficiente un solo enfoque terapéutico para mitigar la enfermedad. Se requiere del empleo de fármacos combinados con diversos efectos.

Los fármacos más potentes en la reducción viral fueron HCQ (mejor que lopinavir $y$ ritonavir) pero superado por remdesivir, avalado en ensayos clínicos tipo III, amplio uso en China y USA. mportancia de medicamentos no indicados en la etiqueta $y$ medicamentos en investigación en el marco de ensayos clínicos o al menos conocimiento científico que sea

Remdesivir es considerado el mejor seguridad clínica. 


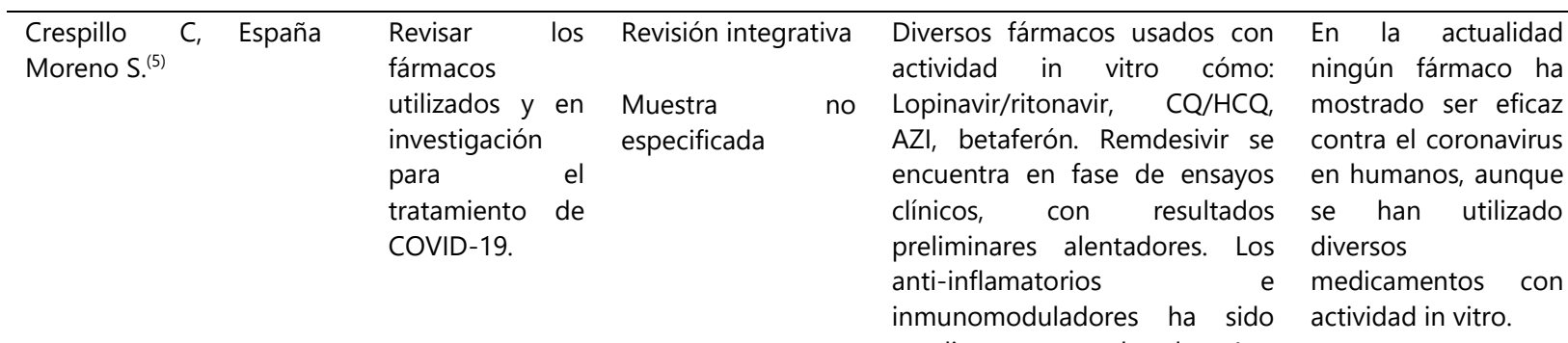

\begin{tabular}{lllll}
\hline Tlayjeh H, & Arabia & Revisar la & Revisión sistemática \\
Mhish O, Enani & Saudita & literatura sobre & y meta-análisis. \\
M, Alruwaili A, & la asociación & Incluyeron estudios \\
Tleyjeh & R, & entre la terapia & observacionales y \\
Thalib L.(24) & & sistémica con ensayos clínicos \\
& CST y los aleatorios (ECA) \\
& resultados de los que evaluaron \\
& pacientes con pacientes tratados \\
& COVID-19. & con CST, con \\
& & & COVID-19.
\end{tabular}

Muestras diversas ampliamente explorado. Los glucocorticoides a dosis bajas por pocos días han mostrado reducción de la mortalidad, aunque los resultados no son aún definitivos. TCZ ha sido ampliamente utilizado, con efectos positivos en estudios observacionales.

Se examinó el efecto de la
terapia sistémica con CST sobre mortalidad a corto plazo. De los 16,977 pacientes hospitalizados (1 ECA y 19 de cohortes) y en otros estudios con 10,278 pacientes (1 ECA y 8 de cohorte). El RR ajustado agrupado fue 0,92 (IC 95\%: 0.69 a 1.22, I2=81,94\%). Cuatro estudios de cohortes examinaron el efecto de la CST sobre el resultado combinado de muerte, ingreso en la $\mathrm{UCl}$ y necesidad de ventilación mecánica. El RR ajustado combinado fue 0.41 (0.23-0.73, $12=78,69 \%)$. Seis de cohortes examinaron el efecto de la CST sobre el aclaramiento viral retardado. EI RR ajustado agrupado fue 1.47 (IC 95\% 1.11$1.93,12=43.38 \%$ ).

\begin{tabular}{lllll}
\hline Díaz & E, España & $\begin{array}{l}\text { Ofrecer } \\
\text { actualización de la } \\
\text { Amezaga- }\end{array}$ & $\begin{array}{l}\text { Revisión } \\
\text { integrativa }\end{array}$ \\
Menéndez R, que se está & \\
Vidal-Cortés P, & $\begin{array}{l}\text { aplicando en la } \\
\text { actualidad. }\end{array}$ & $\begin{array}{l}\text { Muestras } \\
\text { diversas en los } \\
\text { Escapa MG, }\end{array}$ & & $\begin{array}{l}\text { diferentes } \\
\text { Subeviola B, }\end{array}$ \\
Serrano- & & estudios
\end{tabular}

Lázaro $\mathrm{A}$ et al. (27)

Se usan varias terapias con
diversas acciones. Efecto antivírico: lopinavir/ritonavir, remdisivir, HCQ y AZI, Interferon $B$, remdesivir, la mortalidad global fue $13 \%$ ( $18 \%$ con ventilación mecánica, $5 \%$ los no ventilados). No se asoció a mejoría clínica. El TCZ se indica en pacientes con mediana afección y no en casos graves. La Comisión Nacional de Salud de China y otros expertos recomiendan su empleo en pacientes críticos con elevación de IL-6. La evidencia del tratamiento antiinflamatorio con CST es muy limitada. Se observó que el anticoagulante se asoció con disminución de

\section{No en todos los estudios, los CST se asociaron en la reducción de la mortalidad a corto plazo, pero se observó cambios en el tiempo de la eliminación viral en pacientes hospitalizados de diferente gravedad con COVID-19.}

\section{Se destaca la falta de terapias probadas y la necesidad de ensayos clínicos que permitan establecer pautas de tratamiento claras y objetivas. Se usan diferentes terapias con modificaciones rápidas en los protocolos.}




\begin{tabular}{|c|c|c|c|c|c|}
\hline & & & & $\begin{array}{l}\text { mortalidad (HRa 0.86, por día, IC } \\
95 \% 0.82-0.89, p<0.001) \text {. }\end{array}$ & \\
\hline $\begin{array}{l}\text { Gonzales- } \\
\text { Zamora J, } \\
\text { Quiroz T, Vega } \\
\text { A. }{ }^{(28)}\end{array}$ & USA & $\begin{array}{l}\text { Presentar el estudio } \\
\text { de caso en paciente } \\
\text { masculino con } \\
\text { neumonía asociada } \\
\text { a COVID-19. }\end{array}$ & Estudio de caso & $\begin{array}{l}\text { Paciente con SARS-CoV-2, } \\
\text { inicialmente recibió ceftriaxona } \\
\text { y AZI, esta última reemplazada } \\
\text { por HCQ, al no mejorar se indica } \\
\text { remdesivir en una dosis de } 200 \\
\text { mg IV al día y luego } 100 \text { mg IV } \\
\text { diarios durante } 4 \text { días, } \\
\text { combinado con prednisolona } \\
\text { por aumento de IL-6. El paciente } \\
\text { mejoró de manera significativa. }\end{array}$ & $\begin{array}{l}\text { La combinación de } \\
\text { remdesivir y } \\
\text { metilprednisolona } \\
\text { debe considerarse en } \\
\text { casos de neumonía } \\
\text { grave por COVID-19, } \\
\text { para contrarrestar el } \\
\text { daño viral y controlar } \\
\text { la inflamación. }\end{array}$ \\
\hline $\begin{array}{l}\text { Organización } \\
\text { Panamericana } \\
\text { de la Salud } \\
\text { (OPS), OMS. (29) }\end{array}$ & USA & $\begin{array}{l}\text { Recomendar el uso } \\
\text { de ivermectina para } \\
\text { el tratamiento de } \\
\text { COVID-19 }\end{array}$ & $\begin{array}{l}\text { Revisión } \\
\text { integrativa } \\
\text { rápida de todos } \\
\text { los estudios } \\
\text { humanos in } \\
\text { vitro } \\
\text { (laboratorio) e in } \\
\text { vivo (clínicos) de } \\
\text { COVID-19. } \\
\text { Muestra no } \\
\text { especificada }\end{array}$ & $\begin{array}{l}\text { La declaración del Comité de } \\
\text { Expertos de ivermectina } \\
\text { enfatizó su eficacia para reducir } \\
\text { la carga viral en cultivos de } \\
\text { laboratorio, a niveles de } \\
\text { dosificación muy superiores a } \\
\text { los aprobados por FDA en el } \\
\text { tratamiento de enfermedades } \\
\text { parasitarias en humanos. Esta } \\
\text { instancia señala evidencia } \\
\text { insuficiente de la ivermectina } \\
\text { para reducir la carga viral en } \\
\text { pacientes con COVID-19. }\end{array}$ & $\begin{array}{lr}\text { Los estudios } & \text { de } \\
\text { ivermectina } & \\
\text { presentan elevado } \\
\text { sesgo, muy poca } \\
\text { certeza de } & \text { la } \\
\text { evidencia y } & \text { la } \\
\text { existente } & \text { es } \\
\text { insuficiente } & \text { para } \\
\text { llegar a } & \text { una } \\
\text { conclusión sobre sus } \\
\text { beneficios y daños. } \\
\text { La OPS } & \text { no } \\
\text { recomienda } & \text { usar } \\
\text { ivermectina en } & \text { el } \\
\text { tratamiento } & \text { de } \\
\text { COVID-19. } & \end{array}$ \\
\hline $\begin{array}{l}\text { Cao B, Wang } \\
\text { D, Liu Wen, } \\
\text { Wang J, Fan J, } \\
\text { Ruan L, et al. } \\
\text { (30) }\end{array}$ & Inglaterra & $\begin{array}{l}\text { Evaluar la eficacia de } \\
\text { lopinavir/ritonavir, } \\
\text { de acuerdo al } \\
\text { tiempo y la mejora } \\
\text { clínica. }\end{array}$ & $\begin{array}{l}\text { Ensayo aleatorio } \\
\text { controlado. } \\
\text { Pacientes } \\
\text { adultos } \\
\text { internados con } \\
\text { COVID-19 (99 } \\
\text { grupo } \\
\text { experimental y } \\
100 \quad \text { grupo } \\
\text { control). } \\
\text { Mediciones } 14 \text { y } \\
28 \text { días }\end{array}$ & 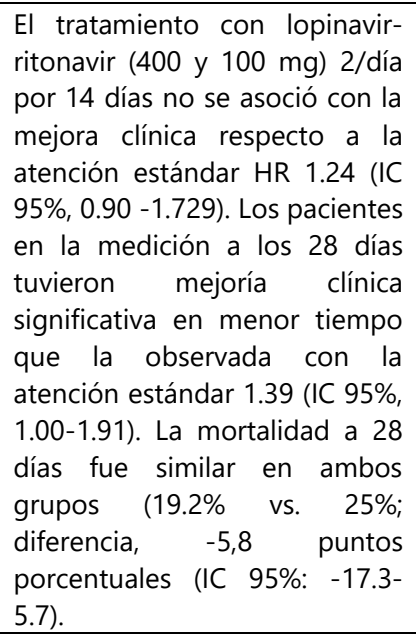 & $\begin{array}{l}\text { En los pacientes } \\
\text { adultos graves con } \\
\text { COVID-19, el } \\
\text { tratamiento con } \\
\text { lopinavir/ritonavir a } \\
\text { los } 28 \text { días aceleró de } \\
\text { manera significativa } \\
\text { la mejoría clínica y no } \\
\text { redujo la mortalidad. }\end{array}$ \\
\hline
\end{tabular}




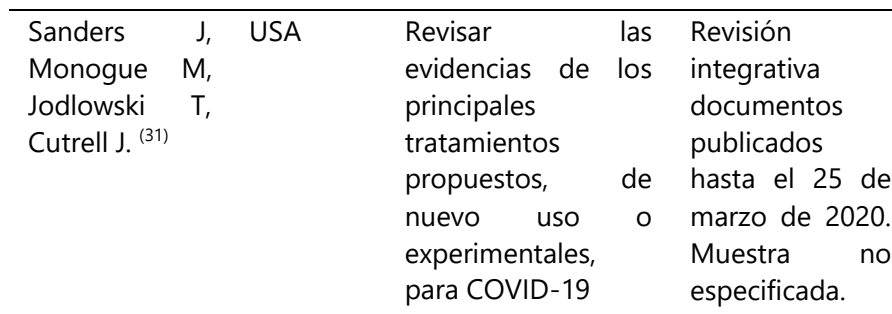

Remdesivir es el fármaco con potente actividad in vitro contra el SARS-CoV-2, pero aún no hay evidencia concluyente. No existen pruebas de alta calidad sobre la eficacia de CQ/HCQ en SARS $O$ el MERS. Lopinavir/ritonavir los datos indican que tiene una función limitada en el tratamiento de COVID-19. No se recomienda los interferones por los datos contradictorios de su acción. El nitazoxanida, es relativamente favorable, pero se requiere de mayores estudios. El plasma convaleciente inmunoglobulina se asoció con una reducción de la mortalidad OR 0.25 (IC 95\%, 0.14-0.45).

Rosenberg E,
Dufort E, Udo
T,
Wilberschied L,
Kumar J,
Tesoriero J,_et
al. ${ }^{(32)}$

USA

$\begin{array}{lll}\text { Describir la } & \text { Estudio de } \\ \text { asociación entre el } & \end{array}$

asociación entre el cohorte uso de la HCQ con o multicéntrico.

$\sin A Z I$, resultados Muestra 1,438

clínicos y pacientes en 25

mortalidad hospitales de

hospitalaria en los Nueva York.

pacientes

con COVID-19.

En todos los grupos de

pacientes hospitalizados con

COVID-19 mediante el ajuste de

riesgos proporcionales de Cox

no se observaron diferencia

significativa en la posible mortalidad. HCQ-AZI (HR, 1.35 (IC 95\%, 0.76-2.40); HCQ (HR, 1.09 (IC 95\%,0.63-1.85) O AZ
Grupos:1) HCQ

$+A Z I, n=735 ; 2)$

HCQ $n=271 ; 3$ )

AZI $n=211$ y 4 )

ninguno de los

fármacos $n=221$ (HR, 0.56 IC 95\%, 0.26-1.21). EI paro cardiaco fue significativamente más probable en los pacientes que recibieron HCQ-AZI (OR ajustado, 2.13(IC 95\%, 1.124.05), pero no fue significativo en HCQ (OR ajustado, 1.91, IC 95\%, 0.96-3.81) o AZ (OR ajustado, 0.64, IC 95\%, 0.271.56).

\begin{tabular}{lll}
\hline Spinner & C, & USA \\
Gottlieb & R, \\
Criner & G, \\
Arribas & J, \\
Cattelan & A, \\
Soriano V, et \\
al. ${ }^{(33)}$
\end{tabular}

Determinar I

eficacia de 5 o 10

días de tratamiento con remdesivir en comparación con la atención estándar en el estado clínico el día 11 de haber iniciado tratamiento.

\section{Ensayo aleatorio en $\quad 105$ hospitales de USA, Asia y Europa. $\mathrm{n}=596$ pacientes al azar Grupos: remdesivir durante 10 días (197), los que lo recibieron durante 5 días (199), y atención estándar (200)}

533 completaron el ensayo. La duración media del tratamiento fue 5 días y 6 días en el grupo de 10 días, con remdesivir. En el día 11, los pacientes del grupo de 5 días de remdesivir tuvieron mejora clínica significativa que los que recibieron atención estándar (OR 1.65; IC 95\%, 1.092.48; $p=.02)$. En el día 11, la distribución en el estado clínico de los que recibieron remdesivir en día 10 y el grupo de atención estándar, no tuvo diferencia significativa, $p=.18$.

\begin{tabular}{|c|c|c|c|c|c|c|}
\hline $\begin{array}{l}\text { Jimbo- } \\
\text { Sotomayor R, } \\
\text { Gómez- } \\
\text { Jaramillo A, } \\
\text { Sánchez X, }\end{array}$ & Ecuador & $\begin{array}{l}\text { Conocer la } \\
\text { efectividad de la } \\
\text { ivermectina para el } \\
\text { tratamiento de los } \\
\text { pacientes con }\end{array}$ & $\begin{array}{l}\text { Revisión } \\
\text { integrativa } \\
\text { Incluyeron } \\
\text { estudios } \\
\text { control }\end{array}$ & caso- & $\begin{array}{l}\text { Ivermectina actúa contra SAR- } \\
\text { CoV-2 in vitro, disminuye la } \\
\text { unión de los factores de } \\
\text { transcripción inducidos por } \\
\text { hipoxia (HIF-1 } \alpha \text { ). La mortalidad }\end{array}$ & $\begin{array}{l}\text { Ivermectina ha } \\
\text { demostrado } \\
\text { actividad antiviral en } \\
\text { contra de SARS-CoV- } \\
\text { 2; sin embargo, aún }\end{array}$ \\
\hline
\end{tabular}

Se requiere de mayores estudios de calidad sobre el tratamiento en la COVID-19. A la fecha no se ha demostrado la eficacia de ninguna terapia, excepto el plasma convaleciente e inmunoglobulina se asociaron levemente con la disminución de la mortalidad.
Entre los pacientes hospitalizados en el área de Nueva York con COVID-19, el tratamiento con HCQ-AZI, HCQ y AZ, en comparación con los que no tenían ningún tratamiento, las diferencias en la mortalidad no fueron significativa. Sin embargo, la interpretación de resultados es limitada por el tipo de diseño del estudio.

Los pacientes con COVID-19 moderado y bajo con remdesivir a los 5 días tuvieron cambios clínicos significativos respecto de los de atención estándar. En mayor tiempo de tratamiento no hubo cambios significativos. 


\begin{tabular}{|c|c|c|c|c|}
\hline $\begin{array}{l}\text { Moreno- } \\
\text { Piedrahita F. } \\
\text { (34) }\end{array}$ & COVID-19 & $\begin{array}{l}\text { observacionales. } \\
\text { Muestra sin } \\
\text { especificar. }\end{array}$ & $\begin{array}{l}\text { fue menor en el grupo de } \\
\text { ivermectina ( } 7.3 \% \text { versus } \\
21.3 \%) \text {, las tasas de mortalidad } \\
\text { global fueron más bajas con } \\
1.4 \% \text { versus } 8.5 \% \text {; HR } 0.20 \text {, IC } \\
95 \%, 0.11-0.37, p<0.0001) \text { no } \\
\text { obstante se necesitan realizar } \\
\text { ensayos clínicos fase } 3 \text { para } \\
\text { comprobar estos hallazgos. }\end{array}$ & $\begin{array}{l}\text { no hay resultados de } \\
\text { ensayos clínicos en } \\
\text { humanos que avalen } \\
\text { su uso. }\end{array}$ \\
\hline $\begin{array}{l}\text { Santillán A, Ecuador } \\
\text { Palacios E. }{ }^{(9)}\end{array}$ & $\begin{array}{l}\text { Conocer } \\
\text { tratamiento }\end{array}$ & $\begin{array}{l}\text { Revisión } \\
\text { integrativa } \\
\text { Muestra no } \\
\text { especificada }\end{array}$ & $\begin{array}{l}\text { Los estudios a la fecha indicaron } \\
\text { que } \mathrm{HCQ} \text { o CQ al igual que } \\
\text { Lopinavir /Ritonavir no son } \\
\text { fármacos eficaces para reducir } \\
\text { la mortalidad en pacientes con }\end{array}$ & $\begin{array}{l}\text { No existe resultados } \\
\text { concluyentes de la } \\
\text { efectividad de los } \\
\text { fármacos contra } \\
\text { COVID-19. }\end{array}$ \\
\hline
\end{tabular}

COVID-19. Remdesivir ayuda a la mejoría clínica, se asoció con una reducción de 5 días en la mediana del tiempo y eliminación del virus.

\begin{tabular}{lllll}
\hline Huamán- & Perú & Sintetizar & la & Revisión \\
Sánchez K. (35) & & evidencia & integrativa. \\
& & disponible sobre la & $16 \quad$ estudios \\
& efectividad & y & observacionales \\
& seguridad de TCZ en & \\
& el & \\
& tratamiento de \\
& COVID-19 &
\end{tabular}

La dosis de TCZ es variable según el peso de la persona y el estado de gravedad. En relación a la mortalidad 15 estudios reportaron este desenlace, cinco sugieren que posiblemente su uso disminuiría la mortalidad por COVID-19, de este grupo solo en tres estudios se hicieron ajustes con otras variables basales o comorbilidades. El TCZ no mostró efectos en la mejoría clínica HR 1.01; IC 95\%, 1.00-1.02; $p<0.006$.

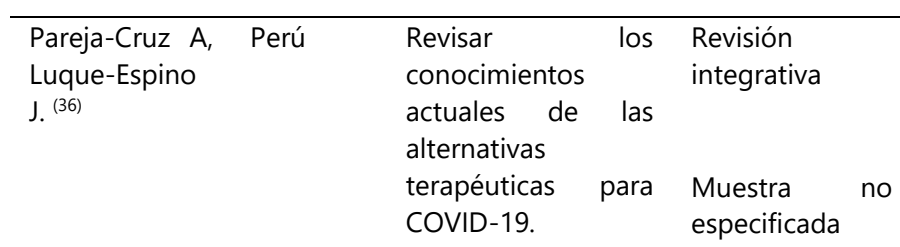

\begin{tabular}{|c|c|c|c|c|c|}
\hline & & COVID-19. & especificada & $\begin{array}{l}\text { hasta medicamentos que } \\
\text { usualmente han sido } \\
\text { empleados } \\
\text { antiparasitarios (CQ e HCQ) o } \\
\text { antibacterianos (teicoplanina y } \\
\text { AZI). }\end{array}$ & $\begin{array}{l}\text { En Perú se usa el } \\
\text { esquema: } C Q, H C Q \text {, e } \\
\text { HCQ/AZI. }\end{array}$ \\
\hline $\begin{array}{l}\text { Benavides } \\
\text { (17) }\end{array}$ & Colombia & $\begin{array}{l}\text { Describir los } \\
\text { tratamientos } \\
\text { de } \\
\text { reposicionamiento } \\
\text { que combaten el } \\
\text { virus }\end{array}$ & $\begin{array}{l}\text { Revisión } \\
\text { integrativa } \\
\text { Muestra no } \\
\text { especificada }\end{array}$ & $\begin{array}{l}\text { Fármacos antimalariales, } \\
\text { antivirales, antibióticos, } \\
\text { glucocorticoides, anticuerpos } \\
\text { monoclonales entre otros están } \\
\text { siendo estudiados; sus } \\
\text { hallazgos aunque preliminares, } \\
\text { mejoran la eliminación del virus. } \\
\text { Los tratamientos de } \\
\text { reposicionamiento fueron HCQ, } \\
\text { AZI+HCQ. }\end{array}$ & $\begin{array}{l}\text { Los tratamientos } \\
\text { combinados cuando } \\
\text { se usan en conjunto } \\
\text { mejoran la } \\
\text { eliminación del virus. } \\
\text { Aun no existe } \\
\text { conclusión definitiva. }\end{array}$ \\
\hline $\begin{array}{l}\text { Moneriz C, } \\
\text { Castro- } \\
\text { Salguedo C. }{ }^{(37)}\end{array}$ & Colombia & $\begin{array}{l}\text { Reconocer } \\
\text { información } \\
\text { disponible } \\
\text { fármacos } \\
\text { potenciales en el }\end{array}$ & $\begin{array}{l}\text { Revisión } \\
\text { integrativa, se } \\
\text { seleccionaron } \\
90 \text { artículos }\end{array}$ & $\begin{array}{l}\text { Los fármacos contra COVID-19, } \\
\text { con resultados positivos fueron } \\
\text { remdesivir y CQ. Lopinavir no } \\
\text { mostró diferencias entre } \\
\text { tratamiento combinado y }\end{array}$ & $\begin{array}{l}\text { Los fármacos contra } \\
\text { COVID-19 se usan en } \\
\text { el manejo de los } \\
\text { síntomas y como } \\
\text { soporte en casos }\end{array}$ \\
\hline
\end{tabular}

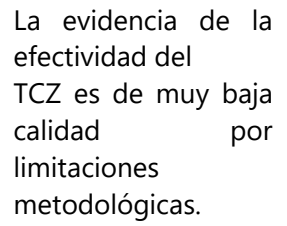




\begin{tabular}{|c|c|c|c|c|c|}
\hline & & $\begin{array}{l}\text { tratamiento } \quad \text { de } \\
\text { pacientes } \\
\text { COVID-19. }\end{array}$ & & $\begin{array}{l}\text { tratamiento estándar en } \\
\text { términos de mejoría clínica y } \\
\text { mortalidad. TCZ su efectividad } \\
\text { está relacionada con el grado } \\
\text { de severidad de la enfermedad. } \\
\text { Interferón, arbidol y } \\
\text { teicoplamina se sugiere pueden } \\
\text { ser útiles. }\end{array}$ & $\begin{array}{lr}\text { graves. } & \text { Varios } \\
\text { estudios } & \text { arrojan } \\
\text { beneficios } & \text { sin } \\
\text { significación } & \\
\text { estadística. } & \text { Se } \\
\text { requiere de } & \text { ensayos } \\
\text { clínicos } & \end{array}$ \\
\hline $\begin{array}{l}\text { Caly L, Druce J, } \\
\text { Catton M, Jans } \\
\text { D, Wagstaff } \\
\text { K. }^{(13)}\end{array}$ & Australia & $\begin{array}{l}\text { Informar el efecto } \\
\text { antiviral de la } \\
\text { ivermectina. }\end{array}$ & $\begin{array}{l}\text { Ensayo invitro, } \\
\text { de cultivo } \\
\text { celular del virus } \\
\text { SARS-CoV-2 y } \\
\text { tratamiento }\end{array}$ & $\begin{array}{l}\text { En laboratorio se infectaron } \\
\text { células epiteliales usadas en } \\
\text { cultivos (Vero-hSLAM) con el } \\
\text { Australia/VIC01/2020 isolate, } \\
\text { posterior de } 2 \text { horas se usó } \\
\text { diluciones seriadas de } \\
\text { ivermectina. Pasadas } 48 \text { horas } \\
\text { se tomó muestra del tejido y se } \\
\text { analizó con la prueba PCR, se } \\
\text { observó una disminución }>5000 \\
\text { veces en el ARN viral }(99.9 \% \text { en } \\
\text { las muestras tratadas con } 5 \mu \mathrm{M} \\
\text { de ivermectina. }\end{array}$ & $\begin{array}{l}\text { El estudio evidenció } \\
\text { el efecto antiviral de } \\
\text { amplio espectro in } \\
\text { vitro de ivermectina } \\
\text { contra las cepas del } \\
\text { SARS-CoV-2. Con } \\
\text { una sola dosis de } 5 \\
\mu \mathrm{M} \text { se controló la } \\
\text { replicación del virus } \\
\text { en } 24-48 \text { horas. }\end{array}$ \\
\hline $\begin{array}{l}\text { Santos S, Salas } \\
\text { C. }{ }^{(39)}\end{array}$ & México & $\begin{array}{lr}\text { Establecer un marco } \\
\text { de referencia de la } \\
\text { clasificación } \\
\text { taxonómica r del } \\
\text { SARS-CoV-2, los } \\
\text { métodos r de } \\
\text { detección } \\
\text { tratamiento } & \\
\text { potencial. } & \\
\end{array}$ & $\begin{array}{l}\text { Revisión } \\
\text { integrativa } \\
\text { Muestra no } \\
\text { especificada. }\end{array}$ & $\begin{array}{l}\text { El tratamiento potencial contra } \\
\text { SARS-CoV-2 en las células Vero } \\
\text { E6 fue remdesivir con efecto de } \\
90 \% \text {. La CQ funciona en el } \\
\text { contagio como en las etapas } \\
\text { posteriores de COVID-19, tiene } \\
\text { efectos antivirales } \\
\text { inmunomodulador. }\end{array}$ & $\begin{array}{l}\text { No se puede afirmar } \\
\text { que se dispone de } \\
\text { tratamientos que } \\
\text { combatan de manera } \\
\text { eficiente y confiable } \\
\text { el SARS-CoV-2. }\end{array}$ \\
\hline $\begin{array}{ll}\text { Gómez } & \text { T, } \\
\text { Diéguez } & \text { G, } \\
\text { Pérez A. }{ }^{(38)} & \end{array}$ & Cuba & $\begin{array}{l}\text { Describir las } \\
\text { alternativas } \\
\text { terapéuticas de } \\
\text { COVID - 19, según } \\
\text { los mecanismos } \\
\text { fisiopatológicos } \\
\text { descritos hasta el } \\
\text { momento. }\end{array}$ & $\begin{array}{l}\text { Revisión } \\
\text { bibliográfica de } \\
31 \text { referencias }\end{array}$ & $\begin{array}{l}\text { Los tratamientos en COVID-19 } \\
\text { son: Inhibidores de la fusión de } \\
\text { membrana de la envoltura viral } \\
\text { (arbidol), Inhibidores de la } \\
\text { proteína endotelial de la } \\
\text { proteasa de la membrana } \\
\text { (TMPRSS2), camostat y } \\
\text { nafamostat, Inhibidores de la } \\
\text { entrada y endocitosis (CQ e } \\
\text { HCQ), Inhibidores 3- } \\
\text { quimotripsina, medicamentos } \\
\text { antivirales de esta enzima } \\
\text { (lopinavir y ritonavir, darunavir, } \\
\text { kalectra) efectiva solo durante la } \\
\text { fase de replicación, Inhibidores } \\
\text { de la ARN polimerasa ribavirina, } \\
\text { favipiravir, redemsevir. Otro } \\
\text { medicamento antibacteriano } \\
\text { usado fue AZI. }\end{array}$ & $\begin{array}{l}\text { Se usan diversos } \\
\text { medicamentos que } \\
\text { han mostrado } \\
\text { efectividad en la fase } \\
\text { del ciclo viral. Los } \\
\text { autores sugieren } \\
\text { focalizar la atención } \\
\text { en HCQ, AZI, kaletra } \\
\text { y el remdesivir con } \\
\text { sus respectivas } \\
\text { combinaciones. } \\
\text { En Cuba la CQ forma } \\
\text { parte del protocolo } \\
\text { del tratamiento, su } \\
\text { uso ha tenido } \\
\text { resultados efectivos. }\end{array}$ \\
\hline
\end{tabular}

Fuente: Elaboración propia

\section{Discusión}

Con base en los hallazgos y análisis de las evidencias científicas más actualizadas, los fármacos que han

presentado actividad favorable contra COVID-19, son antivirales, antibacterianos, antiinflamatorios e inmunomuduladores. Se observa que la estrategia con mejores resultados, menor tiempo y mayor seguridad 
es "Drug Repurposing o Reposicionamiento de Medicamentos", que se refiere al nuevo uso de fármacos aprobados anteriormente para otros eventos diferentes a la indicación original terapéutica, como, por ejemplo, es el uso de HCQ muy utilizado en las enfermedades autoinmunes sistémicas. Por otra parte, la combinación de diversos antivirales versus el uso de uno solo ha controlado mejor la infección, la replicación viral y menor empleo de corticoesteroide. Sin embargo, la mayoría de la literatura analizada coincide en señalar la ausencia de estudios robustos y la necesidad de realizar mayores ensayos clínicos con alta validez científica. ${ }^{(6,8,9,14,15,17,25)}$

Según los diferentes reportes, pareciera que en el tratamiento para la COVID-19, el remdesivir, fármaco análogo de nucleótido, que interfiere con la polimerización del ARN del virus, con actividad in vitro en coronavirus, ha demostrado mayor beneficio significativo en pacientes adultos infectados por el virus en las diferentes etapas del proceso evolutivo de la enfermedad, los pacientes se recuperaron más rápido que con el uso de otros, se señalan mayores resultados favorables en relación a la respuesta de seguridad y eficacia de su aplicación, su uso se incluyó en la guía clínica NIH COVID-19 Treatment Guidelines. (5, 16, 17,22,25$28,31,33,37,38,40,41)$

Por otro lado, el fármaco inmunosupresor TCZ, inhibidor de la interleucina-6 (IL-6), incluido en el tratamiento en SARS-CoV-2 por la Comisión Nacional de Salud de China, evidencia los beneficios en los pacientes, disminuyó el tiempo de hospitalización y complicaciones con dosis de TCZ en etapa temprana vs etapa tardía en la enfermedad aunque aún no se recibía la aprobación de la autoridad sanitaria en ningún

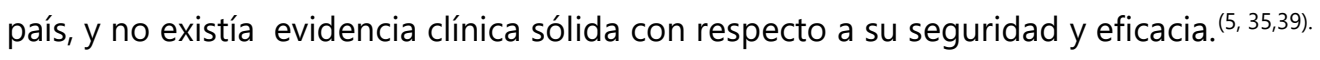

De igual manera, se observa en la literatura que $\mathrm{HCQ} / \mathrm{CQ}$, utilizada desde diciembre 2019 a diciembre 2020, presentó resultados positivos al reducir mayormente la carga viral en pacientes en estadios pre y post-infección, además de contar con evidencia científica, aún no se puede afirmar su aplicación de manera eficiente y confiable ante COVID-19. ${ }^{(10,11,17,23,24,32,40)}$ 
También se menciona el uso de AZI, antibiótico macrólido utilizado eficazmente en las infecciones del tracto respiratorio(14). Asimismo, la Secretaría de Salud de México y la Subsecretaría de Integración y Desarrollo del Sector Salud emplearon el fármaco AZI combinado con HCQ para tratar ciertos pacientes con COVID-19, sin embargo, hay informes variados de su efectividad cuando se usó junto con otros medicamentos en pacientes con secuelas de neumonía ${ }^{(42)}$.

La ivermectina, cuya principal acción es antiparasitario de amplio espectro, también es referido por algunos autores, debido a que su efectividad en condiciones in vitro inhibió la replicación viral de SARSCoV-2, ${ }^{(13,14,34,43)}$ pero investigaciones recientes de la OPS cuestionaron los reportes de los estudios aludiendo el sesgo, poca certeza de evidencia e insuficientes pruebas para llegar a una conclusión válida sobre su beneficio. ${ }^{(2,8,13,29)}$ Se observó en el tratamiento para COVID-19 la inclusión de otras terapias complementarias como plasma de pacientes convalecientes debido a la existencia de la hipótesis de mejoría clínica así como en otras infecciones virales, no obstante, en la actualidad no existe evidencia suficiente para recomendar o desaconsejar el uso de plasma convaleciente en pacientes con COVID-19 (22,23, 25,26, 31).

\section{Conclusiones}

Con base en la revisión integradora que identificó las evidencias científicas sobre el tratamiento farmacológico en los pacientes con COVID-19, se puede concluir que el fármaco que demostró mayor beneficio a los infectados por COVID-19 en las diferentes etapas del proceso evolutivo de la enfermedad, fue remdesivir el cual demostró mejor respuesta de seguridad y eficacia de su tratamiento. Por otro lado, TCZ y los glucocorticoides mostraron resultados favorables, sin embargo, estos aún se encuentran en estudios para corroborar efectividad farmacológica para COVID-19. Actualmente la AZI es indicada dentro del tratamiento para COVID-19 en combinación con otros fármacos, como profilaxis. La HCQ/CQ a pesar de presentar estudios positivos para su uso y ser el fármaco con mayor evidencia científica, aun no se puede afirmar su uso de manera eficiente y confiable. Hasta el día de hoy se están realizando diversos ECA con los 
fármacos antes mencionados, no obstante, los diversos autores señalan que aún no es posible afirmar que se dispone de tratamientos que combatan al COVID-19 de una manera efectiva y eficiente.

El presente trabajo permite actualizar y ampliar el conocimiento de enfermería al familiarizarse sobre las diversas terapéuticas farmacológicas disponibles en la actualidad para contribuir a mejorar las condiciones clínicas en los pacientes con COVID-19 en los diferentes grados de severidad de la enfermedad. Asimismo, facilita al profesional de enfermería reconocer los fármacos más efectivos en la literatura científica, los efectos deseables y colaterales que, sin duda, en la práctica clínica, dicho conocimiento coadyuvará en la implementación de intervenciones oportunas y efectivas que contribuyan en la recuperación de los pacientes.

\section{Conflicto de intereses}

Los autores declararan no tener ningún tipo de conflicto e intereses en relación al artículo.

\section{Financiamiento}

No se requirió financiamiento para realizar este trabajo.

\section{Referencias bibliográficas}

1. Organización para la Cooperación y el Desarrollo Económico [(OECD/The World Bank, 2020), Health at a Glance: Latin America and the Caribbean 2020 [Internet]. OECD Publishing, Paris; 2020 [citado 30 oct 2020]. Disponible en: https://doi.org/10.1787/6089164f-en

2. Organización Mundial de la Salud. Aceleración de la propagación de la COVID-19. [Internet]. OMS [Actualizado 30 oct 2020; citado 30 oct 2020]. Disponible en: https://www.who.int/es/news/item/30-102020-as-covid-19-spread-accelerates-ihr-emergency-committee-urges-focus-on-measures-that-work

3. World Health Organization (WHO). Statement on the fifth meeting of the International Health Regulations, 2005. Emergency Committee regarding the coronavirus disease (COVID-19) pandemic [Internet]. WHO, 2005 [Actualizado día 30 oct. 2020; citado día 30 oct 2020]. Disponible en: https://www.who.int/news/item/30-10-2020-statement-on-the-fifth-meeting-of-the-internationalhealth-regulations-(2005)-emergency-committee-regarding-the-coronavirus-disease-(covid-19)pandemic

4. Shankar A, Dubey A, Saini D, Prakash Ch. Role of complementary an alternative medicine in prevention and treatment of COVID-19: An overhyped hope. Chin J Integr Med [Internet]. 2020 [citado 30 oct 2020];26(8):565-567. Disponible en: https://doi.org/10.1007/s11655-020-2851-y 
5. Crespillo $C$, Moreno S. Abordaje terapéutico en pacientes con infección por coronavirus SAR-COV-2. Act. Farm Terap [Internet]. 2020 [citado 30 oct 2020];18(2):109-120. Disponible en: https://dialnet.unirioja.es/servlet/articulo?codigo $=7487153$

6. Helmy Y, Fawzy M, Elaswad A, Sobieh A, Kenney S, Shehata A. The COVID-19 Pandemic: a comprehensive review of taxonomy, genetics, epidemiology, diagnosis, treatment and control. J. Clin. Med [Internet]. 2020 [citado 30 oct 2020] 9:1225:1-29. Disponible en: https://doi.org/10.3390/jcm9041225

7. Lam S, Lombardi A, Ouanounou A. COVID-19: A review of the proposed pharmacological treatments. Eur J of Pharmacol [Internet]. 2020 [citado 28 ago 2020];886:1-11. Disponible en: https://doi.org/10.1016/j.ejphar.2020.173451

8. Organización Mundial de la Salud. Manejo clínico de la COVID-19. Orientaciones provisionales [Internet]. OMS, $2019 \quad$ [citado 30 oct 2020]. Disponible en: https://apps.who.int/iris/bitstream/handle/10665/332638/WHO-2019-nCoV-clinical-2020.5-spa.pdf

9. Santillán A, Palacios E. Actualización en el tratamiento de COVID-19. Archivos Venezolanos de Farmacología y Terapéutica [Internet]. 2020 [citado 30 oct 2020];39(2):191-194. Disponible en: https://www.revistaavft.com/images/revistas/2020/avft_2_2020/8_actualizacion.pdf

10. Liu J, Cao R, Xu M, Wang X, Zhang $H, H u ~ H$, et al. Hydroxychloroquine, a less toxic derivative of chloroquine, is effective in inhibiting SARS-CoV-2 -2 infection in vitro. Cell Discov [Internet]. 2020 [citado 30 oct 2020];6(16):1-4. Disponible en: https://doi.org/10.1038/s41421-020-0156-0

11. Gautret $P$, Lagier J, Parola $P$, Hoang V, Meddeb L, Mailhe $M$, et al. Hydroxychloroquine and azithromycin as a treatment of COVID19: results of an open-label non-randomized clinical trial, Francia. Int J Antimicrob Agents [Internet]. 2020 [citado 30 oct. 2020];56(1):1-6. Disponible en: https://doi.org/10.1016/j.jantimicag.2020.105949

12. Poschet J, Perkett E, Timmins G, Vojo Deretic. Azithromycin and ciprofloxacin have a chloroquine-like effect on respiratory epithelial cells. Preprints from mesdRxiv and bioRxiv [Internet]. 2020 [citado 30 oct 2020];3(29):1-21. Disponible en: https://doi.org/10.1101/2020.03.29.008631

13. Caly L, Druce J, Catton $M$, Jans $D$, Wagstaff $K$. The FDA approved drug Ivermectin inhibits the replication of SARS-CoV-2 in vitro. Antiviral Res [Internet]. 2020 [citado 30 oct 2020];10(4):787. Disponible en: https://doi.org/10.1016/j.antiviral.2020.104787

14. Choudhary R, Sharma AK. Potential Use of Hydroxychloroquine, Ivermectin, and Azithromycin Drugs in the Fight Against COVID-19: Trends, Scope, and Relevance. New Microbes and New Infect [Internet]. 2020 [citado 30 oct 2020];1(35):1-4. Disponible en: https://www.clinicalkey.es/\#!/content/journal/1-s2.0S2052297520300366

15. Agencia Española de Medicamentos y Productos Sanitarios. Tratamientos disponibles sujetos a condiciones especiales de acceso para el manejo de la infección respiratoria por SARS CoV-2 [Internet]. España; 2020 [citado 30 oct 2020]. Disponible en: https://www.aemps.gob.es/la-aemps/ultimainformacion-de-la-aemps-acerca-del-covid\%e2\%80\%9119/tratamientos-disponibles-para-el-manejode-la-infeccion-respiratoria-por-SARS-CoV-2 -2/

16. Wayah S, Auta R, Waziri P, Haruna E. New insights on potential therapeutic options and vaccines for coronavirus disease-2019. Reviews in Medical Microbiology [Internet]. 2020 [citado 30 oct 2020];0(0):18. Disponible

en: https://journals.Iww.com/revmedmicrobiol/Citation/2021/04000/New_insights_on_potential_therapeuti C_options_and.1.aspx 
17. Benavides V. Reposicionamiento de medicamentos para COVID - 19. Universidad del Valle, Facultad de Salud, Escuela de Ciencias Básicas. Colomb Med (Cali) [Internet]. 2020 [citado 30 oct 2020];50(3):1-11. Disponible en: http://doi.org/10.25100/cm.v51i2.4279

18. Grove SK, Gray JR. Investigación en enfermería. Desarrollo de la práctica enfermera basada en la evidencia. 7 ed. España: Elsevier; 2019.

19. Guevara-Valtier M, Cárdenas-Villarreal V, Hernández-Cortes P. Protocolos de investigación en Enfermería. México: Manual Moderno; 2017.

20. Descriptores en Ciencias de la Salud. Biblioteca Virtual en Salud [Internet]. Organización Panamericana de la Salud; 2021 [citado 30 oct 2020]. Disponible en: http://decs2020.bvsalud.org/cgibin/wxis1660.exe/decsserver/

21. Medical Subject Heading [Internet]. National Library of Medecine. MesH, NIH; 2021 [citado 30 oct 2021]. Disponible en: https://www.ncbi.nlm.nih.gov/mesh/2050325

22. Fan L, Jiang, S, Yang $X$, Wang Z. COVID-19 Drug Treatment in China. Curr Pharmacol Reports [Internet]. 2020 [citado 30 oct 2020];6:146-154. Disponible en:_https://doi.org/10.1007/s40495-020-00218-5

23. Tzu-Han Y, Chian-Ying C, Yi-Fan Y, Chian-Shiu C, Aliaksandr AY, Tzu-Ying Y, et al. Systematic review and meta-analysis of the effectiveness and safety of hidroxychloroquine in treating Covid-19 patients. J Chin Med Assoc [Internet]. 2020 [citado 30 oct 2020];10(1):1-31. Disponible en: https://doi.org/10.1097/jcma.000000000000042 $\underline{5}$

24. Tlayjeh $\mathrm{H}$, Mhish $\mathrm{OH}$, Enani MA, Alruwaili A, Tleyjeh $\mathrm{R}$, Thalib $\mathrm{L}$, et al. Association of corticosteroid use and outcomes in COVID-19 patients: a systematic review and meta-analysis. J Infect Public Heal [Internet]. 2020 [citado 30 oct 2020];13(11):1652-1663. Disponible en: https://www.clinicalkey.es/\#!/content/journal/1-s2.0-S1876034120306638

25. Marto N, Monteiro E. Medicines for the treatment of COVID-19: Awaiting the evidence. Acta Med Port [Internet]. $2020 \quad$ [citado 30 oct 2020];33(7-8):500-504. Disponible en: https://actamedicaportuguesa.com/revista/index.php/amp/article/view/13908/5961

26. Reina J. Remdesivir, la esperanza antiviral frente al SARS-CoV-2. Rev. Esp. Quimioter [Internet]. 2020. [citado 30 oct 2020];33(3):176-179.Disponible en: https://seq.es/wpcontent/uploads/2020/04/reina01apr2020.pdf

27. Díaz E, Amezaga- Menéndez R, Vidal-Cortés P, Escapa MG, Subeviola B, Serrano-Lázaro A, et al. Tratamiento farmacológico de la COVID-19: revisión narrativa de los grupos de trabajo de enfermedades infecciosas y sepsis (GTEIS) y del grupo de trabajo de transfusiones hemoderivados (GTTH). Med. Intensiva [Internet]. 2020 [citado 02 nov 2020];45(2):104-121. Disponible en: https://doi.org/10.1016/j.medin.2020.06.017

28. Gonzales-Zamora J, Quiroz T, Vega A. Tratamiento exitoso con remdesivir y corticoides en un paciente con neumonía asociada a COVID-19: reporte de un caso. Medwave [Internet]. 2020. [citado 30 oct 2020];20(7):e7998. Disponible en: https://www.medwave.cl/link.cgi/Medwave/Estudios/Casos/7998.act.

29. Organización Panamericana de la Salud. Recomendación sobre uso de ivermectina en el tratamiento de COVID-19. OPS [Internet]. 2020 [citado 30 oct 2020]. Disponible en: https://docs.bvsalud.org/biblioref/2020/06/1100598/ops-tratamiento-ivermectina-junio-22-2020.pdf

30. Cao B, Wang D, Liu Wen, Wang J, Fan J, Ruan L, et al. A trial of lopinavir-ritonavir in adults hospitalized with severe COVID-19. N Engl J Med [Internet]. 2020 [citado 30 oct 2020];382:1787-1799. Disponible en: https://www.nejm.org/doi/10.1056/NEJMoa2001282 
31. Sanders JM, Monogue ML, Jodlowski TZ, Cutrell JB. Pharmacologic treatments for coronavirus disease 2019 (COVID-19): A review. JAMA [Internet].2020. [citado 30 oct 2020];323(18):1824-1836. Disponible en: https://pubmed.ncbi.nlm.nih.gov/32282022/.

32. Rosenberg ES, Dufort EM, Udo T, Wilberschied LA, Kumar J, Tesoriero J, et al. Association of treatment with hydroxychloroquine or azithromycin with in-hospital mortality in patients with COVID-19 in New York State. JAMA [Internet]. 2020 [citado 30 oct 2020];323(24):2493-2502. Disponible en: https://jamanetwork.com/journals/jama/fullarticle/2766117

33. Spinner CD, Gottlieb RL, Criner GJ, Arribas JR, Cattelan AM, Soriano VA, et al. Effect of remdesivir vs standard care on clinical status at 11 days in patients with moderate COVID-19. JAMA [Internet]. 2020 [citado 30 oct 2020];324(11):1048-1057. Disponible en: https://jamanetwork.com/journals/jama/fullarticle/2769871

34. Jimbo-Sotomayor R, Gómez-Jaramillo AB, Sánchez $X$, Moreno-Piedrahita F. Ivermectina para el tratamiento de la infección COVID-19. Pontificia Universidad Católica del Ecuador [Internet]. 2020 [citado 20 oct 2020]. Disponible en: https://puceapex.puce.edu.ec/web/covid19-medidas-preventivas/wpcontent/uploads/sites/6/2020/04/ivermectina.pdf

35. Huamán-Sánchez K. Efectividad y seguridad tocilizumab en el tratamiento de COVID-19. Unidad de Análisis y Generación de Evidencias en Salud Pública. Centro Nacional de Salud Pública. Serie síntesis de evidencias COVID-19 [Internet]. Perú; 2020 [citado 30 oct 2020]. Disponible en: https://web.ins.gob.pe/sites/default/files/Archivos/authenticated\%2C\%20administrator\%2C\%20editor/ publicaciones/2020-08-04/SE_23\%20Tocilizumab\%20Covid-19.pdf

36. Pareja A, Luque JC. Alternativas terapéuticas farmacológicas para COVID-19. Horiz. Med (Lima) [Internet]. 2020 [citado 30 oct 2020];20(2):e1216. Disponible en: http://www.scielo.org.pe/pdf/hm/v20n2/1727558X-hm-20-02-e1216.pdf

37. Moneriz C, Castro-Salguedo C. Fármacos prometedores y potenciales para el tratamiento de COVID-19. Revista Chilena de Infectología [Internet]. 2020 [citado 30 oct 2020];37(3):205-215. Disponible en: https://www.revinf.cl/index.php/revinf/article/view/728/397

38. Gómez-Tejeda JJ, Dieguez-Guach RA, Pérez-Abreu MR. Alternativas terapéuticas para el manejo de COVID - 19. Rev Habanera Cienc. Médi [Internet]. 2020 [citado 30 oct 2020]; 19 (Supl):e3328. Disponible en: http://www.revhabanera.sld.cu/index.php/rhab/article/view/3328

39. Santos-Sánchez NF, Salas-Coronado R. Origen, características estructurales, medidas de prevención, diagnóstico y fármacos potenciales para prevenir y controlar COVID-19. Med Wave. [Internet]. 2020 [citado 30 oct 2020];20(8):1-28. Disponible en: https://www.medwave.cl/link.cgi/Medwave/Revisiones/RevisionClinica/8037.act

40. Joo M, Kang M, Youn S, Noh J, Cheong H, Kim W, Jung J. Comparison of antiviral effect for mild-tomoderate COVID-19 cases between lopinavir/ritonavir versus hydroxychloroquine: A nationwide propensity score-matched cohort study. J. Glob. Infect. Dis [Internet]. 2020 [citado 30 oct 2020];102: 275281. Disponible en:_https://doi.org/10.1016/j.jij.2020.10.062

41. Sheahan TP, Sims AC, Leist SR, Schäfer A, Won J, Brown A, et al. Comparative therapeutic efficacy of remdesivir and combination lopinavir, ritonavir, and interferon beta against MERS-CoV. Nat. Commun [Internet]. 2020 [citado 30 oct 2020];11(222):1-14. Disponible en:_https://doi.org/10.1038/s41467-01913940-6 
42. Secretaría de Salud. Propuesta de medicamentos para el tratamiento de COVID-19. Subsecretaría de Integración y Desarrollo del Sector Salud. Dirección General de Planeación y Desarrollo en Salud [Internet]. México; 2020 [citado 30 oct 2020]. Disponible en: http://www.sidss.salud.gob.mx/site2/docs/Propuesta_tratamiento_COVID19.pdf

43. Cepelowicz R, Sherman M, Fatteh N, Vogel F, Sacks J, Rajter J. Use of Ivermectin is associated with lower mortality in hospitalized patients with coronavirus disease 2019: The ICON Study. Chest Infections [Internet]. 2020 [citado 30 oct 2020]. Article in press. Disponible en: https://doi.org/10.1016/j.chest.2020.10.009

Cómo citar este artículo: Melendrez-Arango E, Durán-Aguirre L, Quiñones-Lucero L, Peralta-Peña S, Vargas M. Tratamiento farmacológico en pacientes con COVID-19: una revisión integradora. SANUS [Internet]. 2021 [citado $\underline{\mathrm{dd}} \underline{\mathrm{mm}} \underline{\text { aa] }} ; 6: \mathrm{e} 250$. Disponible en: URL/DOI 